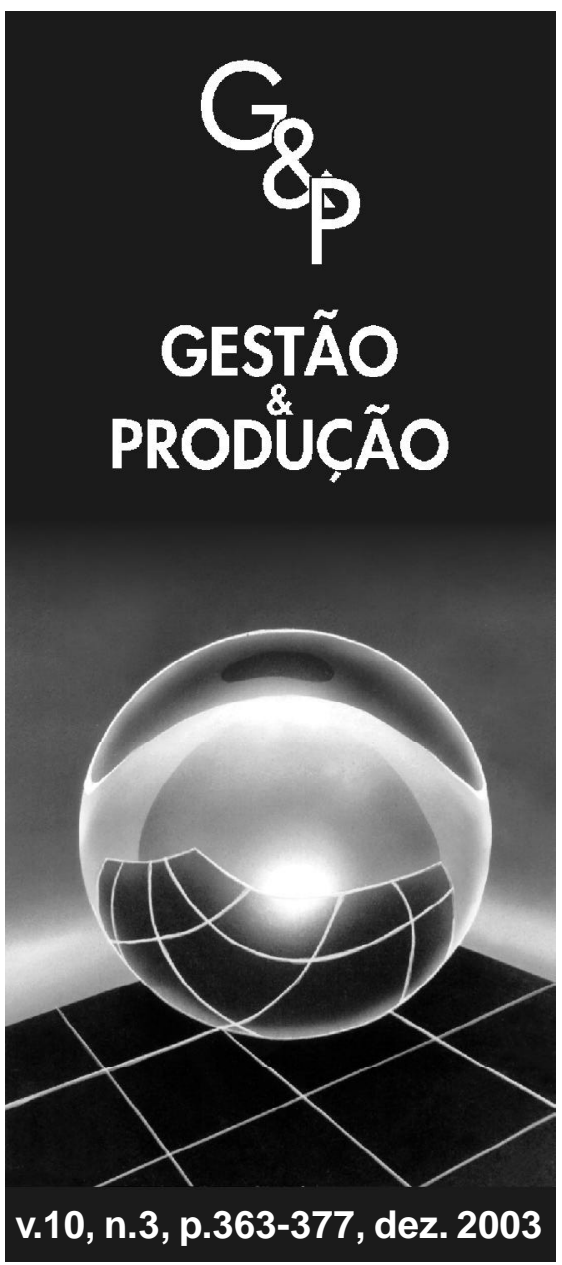

\title{
OUTSOURCING E GERAÇÃO DE VALOR NA INDÚSTRIA DE COMPUTADORES PESSOAIS (PCs): ESTUDO DE MÚLTIPLOS CASOS
}

\author{
Fernando José Barbin Laurindo \\ Marly Monteiro de Carvalho \\ Departamento de Engenharia de Produção \\ da Escola Politécnica da USP, \\ Av. Prof. Almeida Prado, 128, Tr. 2 Biênio, 20 andar, \\ CEP 05508-900, São Paulo, SP, \\ e-mails: fjblau@usp.br e marlymc@usp.br
}

\section{Resumo}

Recebido em 30/6/2003

Aceito em 28/11/2003

Apesar de o conceito de computador pessoal (personal computer-PC) ter surgido nos anos 70, essa indústria realmente deslanchou somente após o lançamento do IBM PC, em 1981. Por meio de uma agressiva estratégia de outsourcing, a IBM rapidamente conquistou o mercado, mas esta estratégia também causou perda de competências internas para seus principais parceiros, Intel e Microsoft, bem como outros revendedores autônomos. No Brasil, atualmente, a indústria de PCs está relegada à montagem de kits importados e também à manufatura das etapas finais do processo de produção de componentes, com pouco valor agregado localmente. Após o término da reserva de mercado, marcado pela súbita abertura aos concorrentes externos, houve desmantelamento da indústria brasileira de PCs e de semicondutores, nos elos de maior valor agregado dessa cadeia. Para obter inserção nas cadeias globais, as empresas brasileiras precisam atingir qualificação nos critérios de desempenho, a fim de participar dos processos de outsourcing. Este artigo visa, por meio de um aparato teórico que relaciona aspectos de outsourcing, inovação, valor e evolução da indústria de PCs, a investigar os impactos desses aspectos na competitividade da indústria de PCs do Brasil e as repercussões para seu crescimento e inserção no mercado global. A abordagem metodológica adotada foi estudo de múltiplos casos, com os seguintes critérios de seleção: diferentes papéis na cadeia de valor, grau de verticalização, principal mercado visado e tamanho da empresa.

Palavras-chave: outsourcing, inovação, indústria de computadores pessoais, estratégia competitiva. 


\section{Introdução}

$\mathrm{N}$ a moderna economia, o domínio tecnológico tem sido enfatizado como elemento de progresso no âmbito tanto das empresas como dos países.

Para Drucker (1998), “o cenário econômico atual está sendo moldado por duas forças poderosas: tecnologia e globalização". A tecnologia está presente na infra-estrutura das atividades econômicas e de toda a sociedade. Dessa forma, a tecnologia da informação, exemplo onipresente da evolução tecnológica, é cada vez mais importante para o desenvolvimento tecnológico, mesmo em áreas não diretamente ligadas a ela, sendo um dos fatores que impulsiona a globalização.

Nesse contexto, a indústria de computadores pessoais ( $\mathrm{PC}$ - personal computer) tem tido especial destaque na evolução da economia mundial, tanto no que se refere aos equipamentos (hardware) como aos programas que possibilitam explorar todo o seu potencial (software).

No entanto, diversas alterações na estrutura e na configuração dessa indústria ocorreram ao longo de sua evolução, desde os anos 70. Essas mudanças transformaram significativamente a cadeia de valor, bem como as relações de governança, principalmente pelas práticas de outsourcing e pelo impacto das inovações.

Nesse âmbito, este artigo visa, por meio de um aparato teórico que relaciona aspectos de outsourcing, inovação, valor e evolução da indústria de PCs, a investigar os impactos desses aspectos na competitividade da indústria de PCs do Brasil e suas repercussões para seu crescimento e inserção no mercado global.

Assim, nas seções iniciais, os conceitos de inovação, desagregação da cadeia produtiva via outsourcing e de acumulação de valor serão discutidos. Em seguida, as particularidades do mercado brasileiro serão apresentadas, destacando a presente situação dessa indústria, após o fim da vigência da lei que garantiu a reserva de mercado de informática durante duas décadas, e apontando as perspectivas para seu desenvolvimento.

A abordagem metodológica adotada foi a de estudo de múltiplos casos (Yin, 1991), com os seguintes critérios de seleção: diferentes papéis na cadeia de valor, grau de verticalização, principal mercado visado e tamanho da empresa.

Com base nesses critérios, três empresas foram selecionadas para os estudos de casos: um fabricante que integra a produção de semicondutores e a montagem de PCs; o maior montador de PCs do Brasil; e um pequeno produtor da economia informal (grey market). Entrevistas foram realizadas com executivos e profissionais de diferentes áreas e de vários níveis hierárquicos.

\section{A evolução da indústria mundial de computadores pessoais}

$\mathrm{O}$ conceito de computador pessoal (PC) firmou-se como ferramenta de uso profissional a partir da $2^{2}$ metade da década de 1970 , com o microcomputador da Apple e a planilha eletrônica (na época o Visicalc). Contudo, o grande salto em sua disseminação ocorreu no início dos anos 80 , quando a IBM lançou sucessivamente o IBM PC. (1981), o PC XT (1983) e o PC AT (1984). O PC representou uma atraente alternativa para os usuários e as empresas, em termos de desempenho (considerando hardware e software) e de custo (Sikonowicz, 1986; Sachs, 1986).

Diversos outros fabricantes surgiram, produzindo os chamados "compatíveis" ou "clones" do IBM PC, já que o hardware era baseado em uma "arquitetura aberta". Nenhuma parte era exclusiva da IBM, pois, por intermédio de uma agressiva estratégia de outsourcing, passou a produção das diversas partes que compõem o PC a outras empresas. Desde então, sucessivas melhorias no hardware e nos softwares têm elevado o potencial dos PCs em um ritmo cada vez maior.

A produção e o desenvolvimento do $\mathrm{PC}$ ao longo dos anos foram baseados nas inovações das sucessivas gerações dos processadores, promovidas pela Intel, e dos sistemas operacionais (antes, o MSDOS e depois, o Windows), pela Microsoft.

De fato, toda a estratégia de produção da IBM baseava-se na terceirização (outsourcing) como meio de rapidamente lançar seu produto, o PC. Essa estratégia permitiu que a IBM, em pouco tempo, 
conquistasse a liderança do mercado, em 1984, três anos após o lançamento do PC. Não obstante, Cheesbrough \& Teece (1996) argumentam que esse processo de terceirização promovido pela IBM causou perda de competências internas da empresa para suas principais parceiras, Intel e Microsoft, e também para revendedores autônomos.

Com o passar do tempo, após a frustrada tentativa da IBM de "fechar a arquitetura" dos PCs (com o PS/2 e seu novo sistema operacional, o OS/ 2), a antiga líder foi perdendo espaço para suas terceirizadas. Não foi somente a perda de market share (de 41\%, em 1985, para 7,5\%, em 1995, época na qual a Compaq tinha 10,5\%) e de lucratividade, mas também a perda da iniciativa e da capacidade de dirigir os rumos da arquitetura dos PCs (Cheesbrough \& Teece, 1996).

A Intel e a Microsoft, que forneciam o processador e o software (sistema operacional), respectivamente, foram crescendo progressivamente e se tornaram poderosos players na indústria de informática, passando a ter a governança da cadeia de produção dos PCs. Além da IBM, Intel e da Microsoft, outros players tiveram papel de destaque ao longo das últimas décadas, conforme ilustra a Figura 1. Pode-se observar que houve mudança nos players nos últimos 20 anos para as diferentes etapas: equipamentos, materiais, componentes, projeto do produto, montagem, sistema operacional, softwares aplicativos, vendas e distribuição e serviços de campo. Todos os players têm enfrentado efetiva concorrência, excetuando a Microsoft, que tem reinado isoladamente (apesar dos defensores do "software livre", como o Linux). Em algumas etapas houve mudança nos players, como na montagem, passando da IBM e da Compaq, na década de 1980, para as manufaturas contratadas (CEM - Contracting Equipment Manufacturers), como a Solectron e a Celestica. Em meados dos anos 90, a Dell Computer despontou, principalmente, nas etapas de vendas e distribuição, nas quais demonstrou competências distintivas (Christensen et al., 2001).

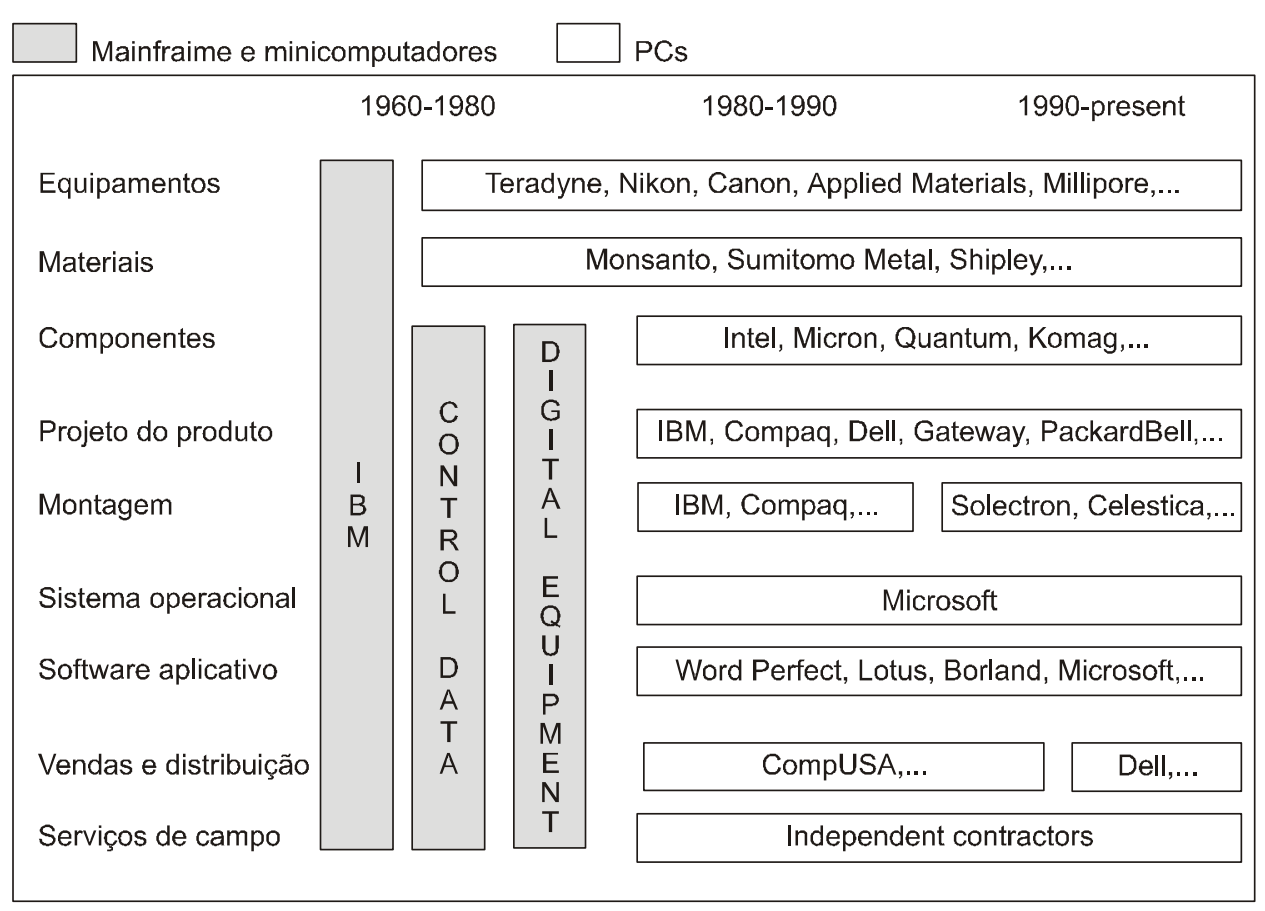

Figura 1 - A desintegração da indústria de computadores (Christensen et al., 2001). 
Outros componentes usados na produção dos PCs utilizam outros tipos de semicondutores além dos processadores, embora não estejam inseridos na mesma cadeia de valor, quais sejam:

- memórias DRAM (Dynamic Random Access Memory);

- memórias SRAM (Static Random Access Memory - usadas na memória "cache");

- memórias flash (EPROM - Erasable and Programmable Read Only Memory, usadas na BIOS - Basic Input and Output System).

Outros chips são usados nas placas-mãe, fazendo as funções exercidas anteriormente por placas de circuito impresso, como controladoras de vídeo e discos, bem como fax-modem.

As memórias dos três tipos citados são produzidas por diversos fabricantes, com grande volatilidade de preços e usualmente consideradas quase como commodities. Nota-se que algumas dessas memórias também podem ser usadas em equipamentos de comunicação e de consumo, como na telefonia celular (Amato et al., 2002).

Os processadores são fabricados pela Intel (78\% do mercado em 2001) e pela AMD. Há outros pequenos fabricantes, de pouca expressão e de participação insignificante no mercado (dentre os pequenos destacou-se a Cyrix). A AMD, que tradicionalmente vendia produtos similares aos processadores da Intel (com uma defasagem no tempo e a um preço mais baixo), passou a produzir processadores que rivalizam ou mesmo superam em desempenho os produzidos pela Intel. Com isso, aumentou significativamente sua parcela de mercado nos últimos anos. Em reação, a Intel aumentou o ritmo de lançamento de novos produtos.

Grande parte do sucesso da Intel se deve à parceria com a Microsoft, pois os requisitos dos novos sistemas operacionais alavancaram novas funcionalidades de processadores. Ao mesmo tempo, as potencialidades dos novos processadores demandam aperfeiçoamentos nos sistemas operacionais. Essa parceria vitoriosa (Microsoft e Intel) tende a se repetir em outras cadeias, como mostra a recente decisão das duas empresas de atuarem juntas no mercado de telecomunicações.

O ritmo dessas mudanças, como já comentado, é ditado pelos fabricantes de processadores e de softwares básicos, que detêm a governança na indústria de PCs (Christensen et al., 2001; Carvalho \& Laurindo, 2002; Laurindo \& Carvalho, 2003).

Além da mudança do papel desempenho pelos players ao longo dos anos, houve modificações importantes relativas à distribuição geográfica de produtores de semicondutores e PCs. Constata-se que essas indústrias passaram por um processo de relocalização, fortemente concentrado no sudeste asiático, para onde migraram as novas plantas dos principais players. Concomitantemente, foram fechadas várias plantas na Europa e nos Estados Unidos. Destaca-se, finalmente, que a América Latina, incluindo o Brasil, está fora do roteiro recente de investimentos dessa indústria (exceto pela planta da Intel na Costa Rica).

A lógica de localização da indústria de PCs não envolve somente $o$ aspecto escala, mas também a legislação tributária e os custos de administração da logística. Toda a concentração que tem ocorrido gera externalidades, promovendo expertise local e abundância de mão-de-obra qualificada (Laurindo \& Carvalho, 2003). Lundvall (1992) destaca que a atividade inovadora é um processo intrinsecamente social e coletivo, depende fundamentalmente das interações entre os agentes e é chamado de aprendizado pela interação (learning-by-interaction).

Finalmente, deve-se ressaltar que os investimentos das novas plantas construídas no sudeste asiático, feitos no início do século XXI em uma conjuntura otimista, associados ao declínio nas vendas de PCs, fato sem precedentes nessa indústria, repercutiu ao longo de toda a cadeia, levando a um excesso de capacidade nessa indústria (Amato et al., 2002). 


\section{Inovação, outsourcing e geração de valor na Indústria de PCs}

Ainda que alguns autores argumentem que a ter-ceirização é crucial para a inovação, Cheesbrough \& Teece (1996) alertam que isso nem sempre é verdadeiro. Para esses autores, as inovações podem ser autônomas ou sistêmicas, e cada um desses dois tipos resulta em configurações diferentes para a cadeia de suprimentos. As inovações autônomas podem ser desenvolvidas independentemente de outras inovações; nessas condições, uma configuração de cadeia mais descentralizada, com maior grau de virtualização, seria possível.

Cabe discutir o que significa "virtual", palavra que tantas vezes surge quando se fala da Nova Economia e da Internet. De acordo com Chandrashekar \& Schary (1999), no âmbito das empresas e da cadeia de suprimentos, a virtualidade pode ter três diferentes significados. Primeiramente, pode significar toda comunicação via computador substituindo a participação humana. $\mathrm{O}$ segundo significado está relacionado à idéia de uma "supraorganização", na qual cada parceiro tem papel específico. Finalmente, o terceiro significado é o do desenvolvimento de organizações reunidas fundamentalmente por redes de TI, nas quais o estabelecimento da rede ainda demanda contato pessoal, mas que, uma vez estabelecida a rede, as transações futuras são todas eletrônicas.
Por sua vez, as inovações sistêmicas geram valor apenas quando acompanhadas de outras inovações. Dessa forma, uma organização centralizada e integrada seria necessária para coordenar essas inovações. Para Cheesbrough \& Teece (1996), uma melhor solução seria um mix de integração e virtualização, esta última adotada de maneira seletiva e cautelosa. Assim, para construir uma organização voltada à inovação, os executivos devem verificar qual tipo de inovação está ocorrendo e também avaliar se as competências e as capacidades necessárias para produzir tal inovação estão disponíveis no mercado ou se é necessário desenvolvê-las.

Da combinação desses fatores resultam diferentes abordagens recomendadas, conforme pode ser observado na Figura 2. Apenas em uma situação (inovações autônomas com capacidades existentes no mercado) os autores recomendam a terceirização: na abordagem "virtual". Idéia similar foi concebida por Christensen \& Overdorf (2000), que consideraram que a natureza das mudanças pode ser explicada por meio de dois conceitos básicos: inovações de sustentação e inovações de ruptura. As inovações de sustentação visam a melhorar o desempenho de um produto já conhecido por um mercado também conhecido, enquanto as inovações de ruptura implicam a criação de novos mercados. As empresas devem ser capazes de lidar com seus recursos, processos e valores de maneira a definir uma estrutura única que combine esses fatores.

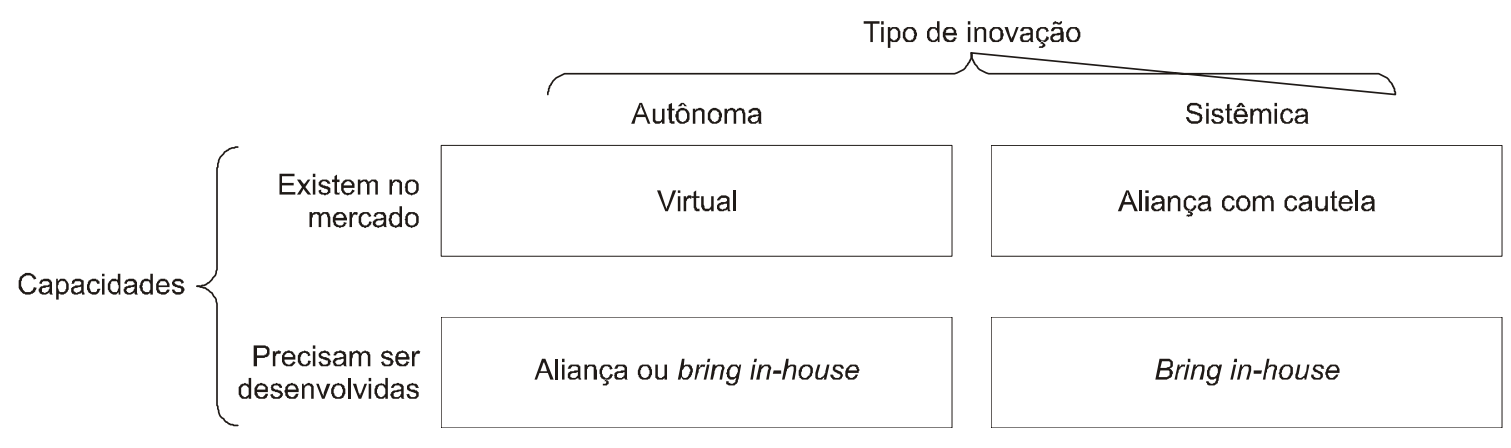

Figura 2 - Adequando organização à inovação (Chesbrough \& Teece, 1996). 
Para Christensen et al, (2001), à medida que a tecnologia se desenvolve, o desempenho do produto ultrapassa as necessidades e as expectativas dos consumidores. Dessa forma, as empresas que montam os produtos passam a competir basicamente por liderança em custos [conforme a classificação de Porter (1979)], pois deixa de ser importante a integração das atividades como fator de geração de melhorias no produto, capaz de gerar diferenciação e, portanto, vantagem competitiva.

$\mathrm{Na}$ indústria de PCs, a estrutura terceirizada levou à geração de valor a se concentrar na produção (e no desenvolvimento) dos processadores e do sistema operacional, na produção de equipamentos para fabricação de memórias DRAM e nos produtores de cabeças de leitura e gravação dos hard disks, conforme ilustra a Figura 3 (Christensen et al., 2001).

A vantagem na integração das atividades passa para elos a montante da cadeia de valor ou do sistema de valor, na nomenclatura de Porter \& Millar (1985), conforme ilustra a Figura 4. Nesses elos, ainda se buscam melhorias de desempenho mediante inovações tecnológicas capazes de levar à diferenciação dos produtos usados na montagem final. Portanto, esses elos devem manter-se como etapas integradas da cadeia de valor. Essa transferência da vantagem na integração pode migrar ainda mais acima na cadeia, atingindo os fabricantes de equipamentos usados na produção de componentes ou outros insumos, caso haja desintegração no elo anterior.

Nesse contexto, as empresas deixaram de competir pelas diferenças de seus produtos, com exceção da Apple, que continua a vender microcomputador com soluções únicas em termos de hardware e sofware.

Assim, as empresas deveriam buscar novas formas de competir nessa indústria. Dentre elas deve-se citar o exemplo da Dell, que, ao apresentar uma nova forma de trabalhar, trouxe um grande impacto a seus resultados. A Dell analisou a concorrência direta e percebeu que seus principais concorrentes (como IBM, Compaq e HP) vendiam por meio de revendedores intermediários.

Desenvolvendo grande sintonia na cadeia de suprimentos, reduziu os prazos e os custos de produção e distribuição e, com o impulso fundamental do e-commerce via Internet, passou a vender diretamente a seus clientes. Além disso, a Dell concentrou-se na venda a empresas, para quem podia vender máquinas de maior valor que incorporavam os mais recentes avanços tecnológicos.

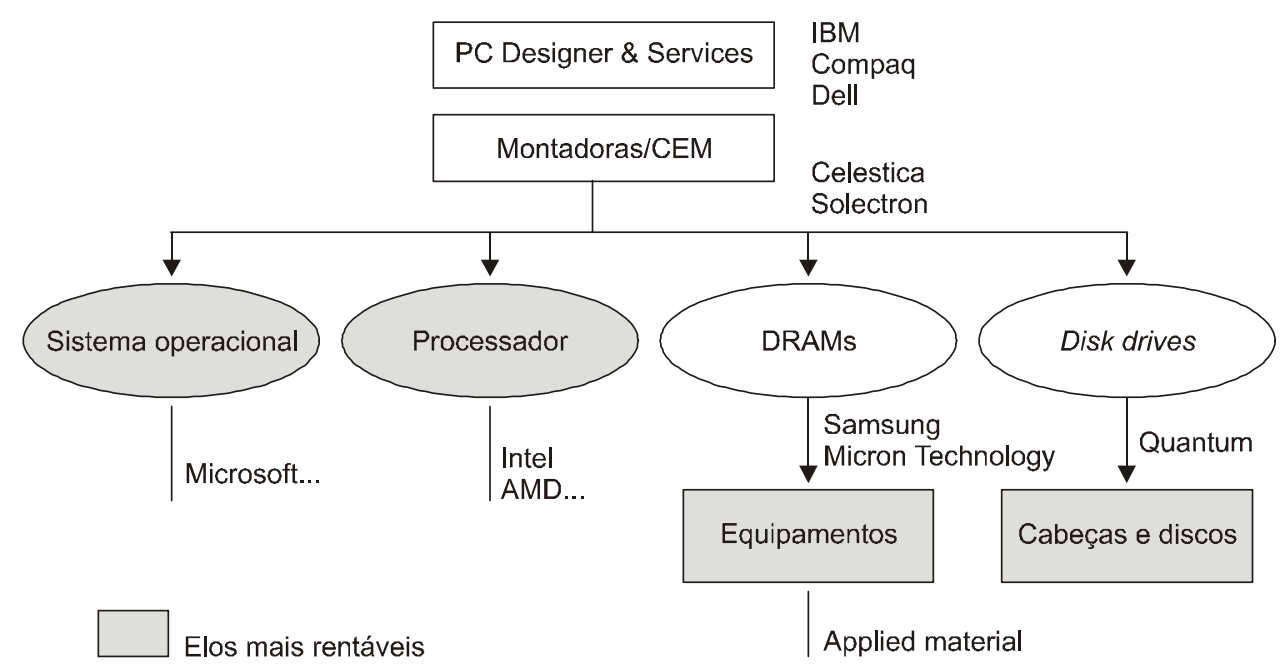

Figura 3 - Cadeia de valor da indústria de PCs (adaptada de Christensen et al., 2001). 


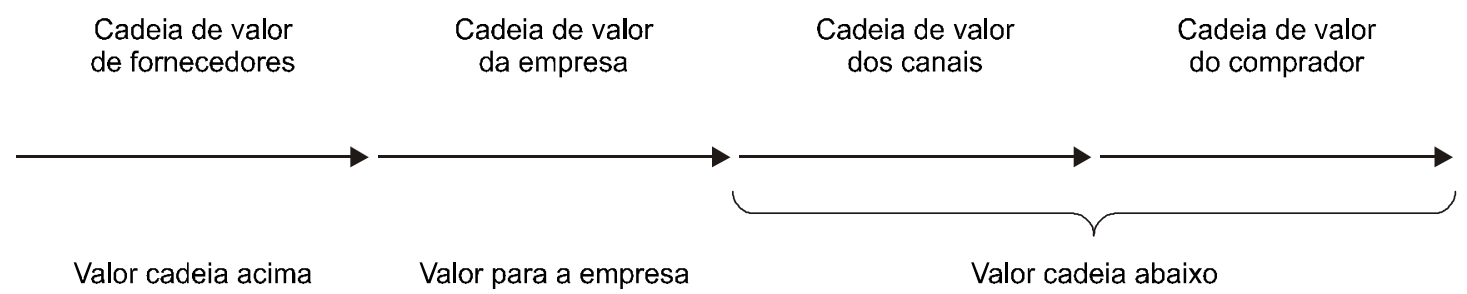

Figura 4 - O sistema de valor (Porter \& Millar, 1985).

$\mathrm{Na}$ fórmula da Dell, não somente as vendas são diretas aos clientes, mas a produção somente é iniciada quando um pedido for feito. A empresa também foca a prestação de serviços e a assistência técnica, tanto por meio de telefone como de atendimento em domicílio (Reid \& Sanders, 2002).

Dessa forma, representou um modelo importante de diferenciação, não baseada no produto, mas na gestão da cadeia de valor, no atendimento e nos serviços prestados, que permitiram à empresa se tornar a maior empresa do setor de PCs em 2001, ainda que com intensa disputa com a HP (Carvalho \& Laurindo, 2003).

Nesse contexto de aumento do outsourcing, um último componente do quadro analítico proposto são as alianças logísticas, que assumiram papel de destaque na formulação da estratégia das empresas. Segundo Bowersox (1990), o conceito de alianças logísticas é caracterizado pela cooperação, muitas vezes com base em entendimentos informais, formando um pacto de negócios no qual as partes buscam os benefícios da sinergia do trabalho conjunto. As parcerias logísticas distinguem-se de outros modelos cooperativos de negócios pela ligação muito forte entre os atores que praticamente criam uma organização estendida com seu próprio papel, regras, valores e objetivos.

As formas mais comuns de aliança logística envolvem um produtor e um provedor de serviço. Pode haver a combinação de recursos de mais de um provedor de serviço. Exemplos de provedores seriam companhias de armazenamento ou de transporte rodoviário. Outros formatos comuns de aliança logística são o alinhamento vertical entre dois ou mais produtores e o alinhamento horizontal. O primeiro geralmente é marcado pela transferência de estoques e o segundo, pela venda para a mesma base de clientes, ambos podendo incluir um provedor de serviços.

\section{A indústria de PCs no Brasil}

A indústria brasileira de PCs, assim como toda indústria de semicondutores e componentes eletrônicos, desempenhou papel mais importante durante os anos 70 e 80, pela importância dada na época à política de substituição de importações (Melo et al., 2001).

Durante a década de 1970, houve destacado crescimento de produtos eletrônicos no mercado brasileiro, seguido, na década de 1980, por um processo de implementação de instalações para a produção local de componentes eletrônicos. Esse processo estava alinhado a um movimento mundial de descentralização dessa indústria. No início dos anos 80, mais de 20 importantes fabricantes de componentes eletrônicos estavam instalados no Brasil, destacando-se Phillips, Philco, Semikron, Texas, Siemens, NEC, entre outros. Entretanto, deve-se enfatizar que, no caso de semicondutores, apenas as etapas finais de teste e montagem eram realizadas localmente, com exceção da Philco e da Semikron, que também realizavam a difusão de componentes.

Uma política nacional de informática (PNI) foi formulada e desenvolvida nos anos $70 \mathrm{em}$ face do grande crescimento da demanda por computadores, que era suprida basicamente por importações. Esse fato causava preocupações relativas 
à dependência tecnológica, acentuada pela tendência de disseminação das máquinas de pequeno porte. Assim, a PNI, inicialmente, restringiu a produção de minicomputadores apenas aos fabricantes nacionais. A coordenação da PNI foi assumida em 1979 pela SEI (Secretaria Especial de Informática), cujas atribuições incluíam aspectos da produção de computadores, automação, software e componentes. Com o surgimento e a disseminação dos PCs, a SEI passou a exigir que todo o projeto, além da produção, fosse nacional para esse tipo de equipamento (Melo et al., 2001).

Dessa forma, na década de 1980, com o amparo da reserva de mercado, que excluía competidores estrangeiros, e com a crescente importância da Tecnologia da Informação para as empresas, o número de fabricantes brasileiros de minicomputadores e de PCs cresceu vertiginosamente. Apesar de a nacionalização envolver mais a parte eletrônica propriamente dita, excluindo a parte de "mecânica fina", alguns fabricantes nacionais produziam partes importantes de impressoras e discos rígidos. Além disso, houve importantes investimentos na produção de ASICs (applied specific integrated circuits) e no encapsulamento de memórias, principalmente por fabricantes ligados a grandes conglomerados financeiros. A atuação da SEI, embora legitimada pela Lei de Informática (Lei 7232, de 29/10/1984), passou a ser dificultada pelos problemas econômicofinanceiros do País e das empresas nacionais, por pressões externas e pela crescente insatisfação do mercado.

Com o fim da reserva de mercado no início dos anos 90 e a conseqüente súbita abertura aos concorrentes externos, houve desmantelamento da indústria brasileira de PCs e de semicondutores. Somente alguns poucos fabricantes sobreviveram e a maioria deles mudou sua orientação para um papel de prestadores de serviços, focando o desenvolvimento de software ou nichos específicos, como automação bancária (Melo et al., 2001).

As principais razões para tal colapso foram a falta de domínio do estado da arte da tecnologia e o baixo desempenho nos aspectos custo e qualidade. A exceção mais relevante foi um fabricante de PCs e de memórias, um dos produtores ligados a grandes conglomerados financeiros mencionados anteriormente.

Diante da realidade da competição do mercado mundial, as empresas brasileiras que desejarem se inserir no processo de terceirização, que envolve a produção de PCs em âmbito mundial, necessitam atingir qualificação adequada aos critérios de desempenho exigidos.

De maneira geral, a indústria de PCs no Brasil está reduzida à montagem de kits importados, com baixa agregação de valor local (Laurindo \& Carvalho, 2003). Interessante notar que mesmo itens de pouca complexidade e valor são importados, como nos casos de gabinetes e fontes. Há, ainda, a produção local de cinescópios para monitores de vídeo (Samsung Display Devices, em Manaus, AM).

Cabe salientar que há no Brasil um mercado informal de microinformática, com as mesmas dimensões do mercado formal (o chamado grey market), atendendo ao uso pessoal (Amato et al, 2002).

Ainda que o potencial do mercado brasileiro seja muito grande, a parcela da população que tem acesso aos PCs é muito pequena, estando em torno de $2 \%$ da população. Contudo, nota-se um crescimento muito acentuado impulsionado pela disseminação do uso da Internet, tanto no uso doméstico como no de pequenas e médias empresas que buscam atuar no e-commerce.

\section{Aspectos metodológicos}

Como ressaltado anteriormente, este artigo visa a investigar os relacionamentos de outsourcing presentes na indústria de PCs do Brasil e suas repercussões para seu crescimento e inserção no mercado global. Para isso, é preciso entender como as empresas brasileiras têm competido nesse mercado, suas práticas de outsourcing, e buscar quais são os gargalos para seu desenvolvimento.

Primeiramente, para a compreensão do cenário brasileiro da indústria de PCs, recorreu-se a dados secundários. Em seguida, optou-se por uma pesquisa empírica de caráter exploratório para obtenção de dados primários, desenvolvida 
pela abordagem de estudo de múltiplos casos, o que permitiu analisar como são os relacionamentos entre os elos dessa cadeia e os fatores envolvidos (Yin, 1991; Claver et al., 2000). O modelo teórico para análise baseia-se nos conceitos expostos nas seções anteriores.

Os critérios de seleção dos casos foram: diferentes papéis na cadeia de valor, grau de verticalização, principal mercado visado e tamanho da empresa.

Com base nesses critérios, três empresas foram selecionadas para o estudo de campo:

- um fabricante integrado de produção de semicondutores e de montagem de PCs, doravante denominado de caso "A";

- o maior montador de PCs do Brasil, que será o caso "B";

- um pequeno produtor da economia informal (grey market), que será chamado de caso "C".

As entrevistas semi-estruturadas foram realizadas, nos três casos, com executivos e profissionais de diferentes áreas. Os principais pontos investigados no roteiro de entrevistas diziam respeito aos seguintes aspectos:

- produtos e serviços disponibilizados;

- nível de integração e verticalização;

- relacionamentos verticais e horizontais na cadeia;

- mercado almejado.

\section{Resultado do estudo exploratório: apresentação dos casos estudados}

A coleta de dados primários resultou no quadro analítico apresentado nesta seção. Os casos descritos a seguir são os seguintes: caso "A" - um fabricante integrado de produção de semicondutores e de montagem de PCs; caso "B" - o maior montador de PCs do Brasil; e caso "C" - um pequeno produtor da economia informal.

\subsection{Caso "A"}

A empresa estudada no caso "A" é o segundo maior produtor (em vendas) do mercado brasileiro de PCs e é o maior fabricante da América Latina de placas de circuitos impressos e memórias, com grande expertise no atendimento das necessidades desses itens na área automobilística.

É uma unidade de negócios dentro de uma grande corporação diversificada, cujo negócio principal está no setor financeiro.

Apresenta estrutura parcialmente integrada verticalmente, desde a produção de semicondutores (em suas etapas finais do processo produtivo) até a montagem final dos PCs.

Durante a década de 1980, a empresa produzia a maior parte dos componentes de seus microcomputadores, tal como hard disks, memórias e placas. Até um sistema operacional para PCs, que emulava o MSDOS, foi desenvolvido e comercializado. Contudo, seguindo a tendência dos fabricantes de PCs em âmbito mundial e na esteira do final da reserva de mercado, a empresa passou a adotar uma abordagem de terceirização.

Atualmente, a empresa objeto da análise produz placas de circuitos impressos, memórias DRAM e PCs. Para a indústria de PCs, o caso "A" produz memórias SDRAM (Syncronized Dynamic Random Access Memory) e monta kits de placasmãe de fabricantes conhecidos, como ASUS e PCChips. A maior parte da produção desses itens é destinada a seus próprios PCs, mas também são fornecidos para outros fabricantes. Destaque-se, entretanto, que a produção dos módulos de memórias SDRAM se restringe às etapas de back end, que agregam $30 \%$ do valor ao processo. Portanto, observa-se que a empresa perdeu competências em alguns elos de valor dessa cadeia. Deve-se ressaltar que o tipo de instalação fabril dessa empresa, ainda que não abranja todas as etapas do processo de produção dos semicondutores, requer grande investimento em equipamentos de teste. Além disso, a mudança nos produtos e processos tem ciclos curtos que implicam a obsoletização dos equipamentos em aproxi- 
madamente três anos, o que exige constantes investimentos.

Assim, na classificação de Chesbrough \& Teece (1996), o caso "A" mudou sua estratégia de outsourcing, uma posição bring in-house para uma situação virtual (Figura 5).

No que concerne às relações verticais ao longo da cadeia, os principais fornecedores de waffer de silício estão localizados no sudoeste da Ásia e nos Estados Unidos, destacando-se que todos são empresas intensivas em escala e capital. $\mathrm{O}$ caso "A" vende seus produtos por diferentes canais: lojas próprias, lojas especializadas em eletrônica ou informática e ainda pela Internet. Nota-se que as demais unidades de negócio da mesma corporação são importantes clientes (em especial o banco de varejo), adquirindo equipamentos com configurações mais sofisticadas e com grande valor agregado. A empresa, apesar do porte, está basicamente restrita ao mercado local. A análise da inserção do caso "A" na cadeia pode ser visualizada na Figura 6.

Finalmente, essa empresa adota uma estratégia genérica de enfoque com diferenciação, em que o recorte são clientes corporativos e aqueles que buscam configurações mais sofisticadas, denotando uma preocupação com a gestão da marca (Porter, 1979).

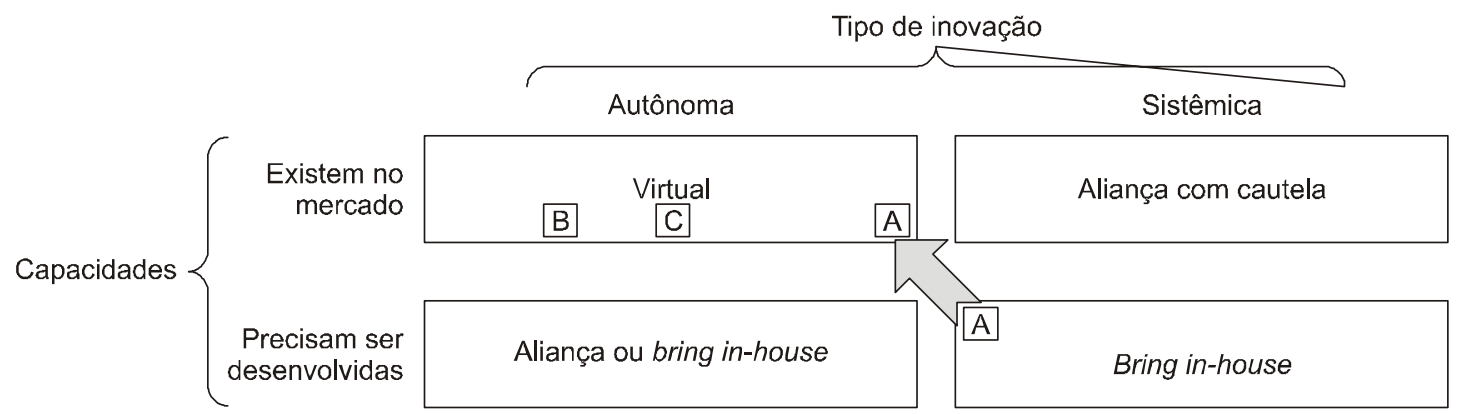

Figura 5 - Adequando organização à inovação nas empresas estudadas (adaptada de Chesbrough \& Teece, 1996).

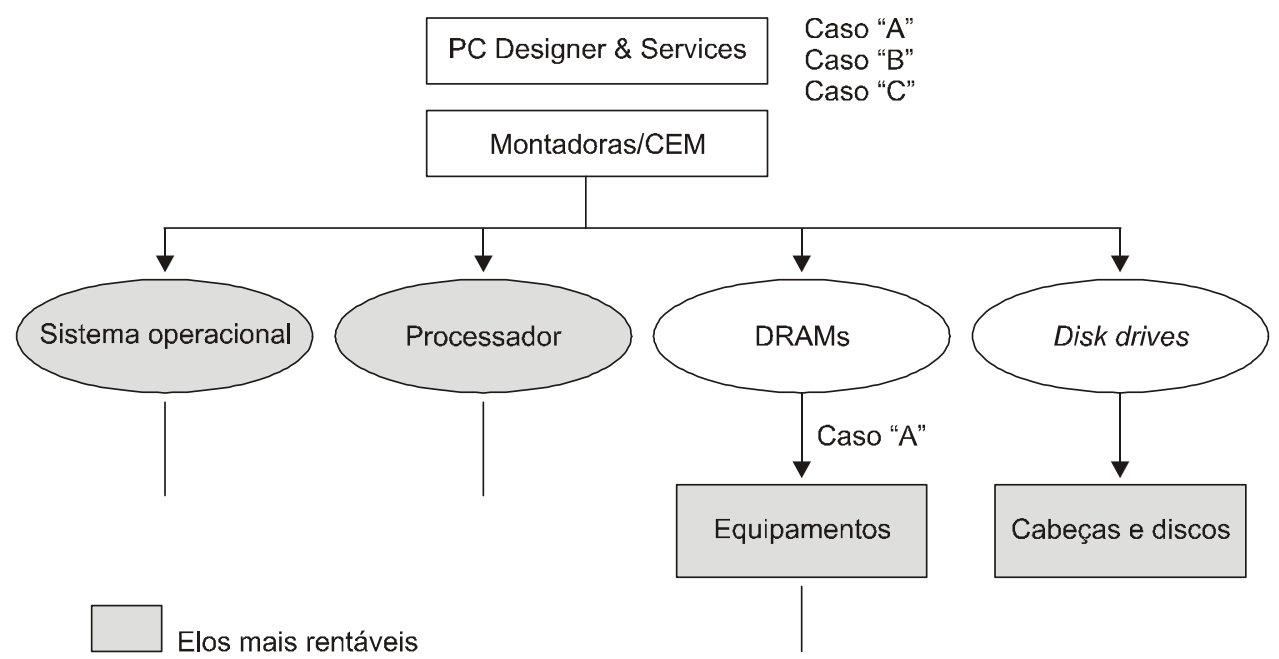

Figura 6 - Distribuição dos casos ao longo da cadeia de valor da indústria de PCs (adaptada de Christensen et al., 2001). 


\subsection{Caso "B"}

A segunda empresa estudada, caso "B", é o maior produtor de PCs desktop do Brasil. Nos anos 90, a empresa era importadora de componentes para montadores locais de PCs, quando decidiu montar seu próprio microcomputador, lançando sua marca própria. Assim, essa empresa, desde o início, adotou uma abordagem virtual na classificação de Chesbrough \& Teece (1996), conforme a Figura 5.

Em razão dessa origem, boa parte do fornecimento provém de grandes fabricantes estrangeiros. A empresa segue uma estratégia de liderança em custos, vendendo principalmente para pequenas empresas e para usuários domésticos em geral. A simplicidade de suas instalações e de sua estrutura organizacional reflete o compromisso com a manutenção de baixos custos.

Por intermédio de uma política bastante agressiva de vendas e de exposição na mídia, o caso "B" conquistou a liderança do mercado brasileiro, com a venda de aproximadamente 200 mil microcomputadores em 2001, atingido inclusive as classes de menor poder aquisitivo.

Como a grande maioria de suas vendas destinase a usuários domésticos, a maior parte dos equipamentos comercializados pela empresa tem configuração simples e barata e está baseada em kits importados. Em consequiência, as margens de lucro são estreitas. Os canais de vendas de seus produtos mais utilizados são lojas de departamento e supermercados. Algumas vezes esses canais demandam uma configuração específica sob encomenda, o que a empresa "B" é capaz de atender adequada e rapidamente, desde que em grandes lotes.

No momento, o caso "B" está empreendendo esforço a fim de aumentar as vendas para o mercado corporativo, no qual maiores margens podem se obtidas. Todavia, essa proposta tem importantes implicações em termos de desenvolvimento de competências e habilidades (Prahalad \& Hamel, 1990), já que o mercado corporativo demanda configurações mais sofisticadas, bem como melhor suporte técnico nas vendas, na assistência e na manutenção. Por outro lado, como a estratégia vigente é de liderança em custo, sua estrutura não foi desenhada para essa nova abordagem. Sua meta é atingir 50\% do total de suas vendas para o mercado corporativo, um salto considerável, já que a proporção atual não excede $14 \%$ do total.

Recentemente o caso "B" começou a produzir seus próprios notebooks (até o momento era representante de notebooks importados de uma marca bem conhecida), com o mesmo padrão competitivo de vender a preços baixos (30\% mais baixos em média do que a concorrência). Seu próximo movimento pretendido é a exportação de PCs, focalizando a América Latina. A síntese da análise na cadeia do caso "B" encontra-se na Figura 6.

\subsection{Caso "C"}

O caso "C" é um pequeno montador de PCs, criado em 1994, que atua na economia informal, no chamado grey market, representativo de grande contingente de pequenos empresários que trabalham dessa forma.

Inicialmente, a empresa vendia upgrades (atualizações de processadores, placas e periféricos) para usuários domésticos. Com o desenvolvimento de suas habilidades e a capacidade em produção e vendas, optou por montar PCs completos, com base em kits importados, de acordo com especificações de seus clientes. A síntese da análise da cadeia do caso "C" encontra-se na Figura 6.

Seus principais fornecedores são intermediários locais que importam produtos da China (e de outros países do Sudeste Asiático) e um intermediário nos Estado Unidos para os componentes mais caros. Dessa forma, pode-se concluir que também esta empresa adota uma abordagem virtual, conforme Figura 5 (Chesbrough \& Teece, 1996).

A evolução de sua prestação de serviços e a venda de produtos é apresentada na Tabela 1.

$\mathrm{O}$ caso " $\mathrm{C}$ " adotou uma estratégia genérica de enfoque com diferenciação, em que privilegia usuários domésticos e microempresários, oferecendo um pacote de produtos e serviços de soluções sob encomenda, com confiabilidade na en- 
trega, com qualidade adequada e bons preços, principalmente por sua condição de empresa da economia informal. Tal abordagem também inclui um bom serviço de pós-vendas. Nessa estratégia, nem sempre opta por fornecedores de menor custo, pois isso pode comprometer a qualidade de seus produtos e, conseqüentemente, sua imagem de confiabilidade, além de implicar um grande aumento de atendimentos de manutenção no período de garantia, o que reduziria suas margens. Sua proposta é ofertar boas soluções de compromisso entre custos e benefícios.

As configurações comercializadas são, em sua maioria, simples e demandam softwares-padrão (como Office da Microsoft).
Destaca-se ainda que, além de consumidores de PCs para uso doméstico, o caso " $\mathrm{C}$ " tem vendido PCs e upgrades e prestado serviços a pequenas empresas.

\subsection{Síntese do estudo exploratório}

Para melhor compreensão do estudo de múltiplos casos, nesta seção será feita uma análise comparativa, cuja síntese se encontra na Tabela 2.

Os tópicos contemplados nesta análise foram: produtos e serviços; estratégia de outsourcing; nível de verticalização; mercado almejado e estratégia genérica.

Tabela 1 - Evolução da proporção de produtos e serviços no caso “C”.

\begin{tabular}{lccc}
\hline Período & Manutenção & Montagem & Upgrade \\
\hline Até 6/2002 & $10 \%$ & $60 \%$ & $30 \%$ \\
Após 6/2002 & $60 \%$ & $20 \%$ & $20 \%$ \\
\hline
\end{tabular}

Tabela 2 - Resumo dos três casos analisados.

\begin{tabular}{|c|c|c|c|}
\hline Tópico & Caso "A" & Caso "B" & Caso "C" \\
\hline Produto/serviço & $\begin{array}{l}\text { - PCs e notebooks, } \\
\text { - Memórias } \\
\text { - Placas }\end{array}$ & - PCs e notebooks & $\begin{array}{c}\bullet \text { PCs } \\
\text { - Manutençãos e } \\
\text { upgrades }\end{array}$ \\
\hline Verticalização & $\begin{array}{l}\text { Parcial a montante } \\
\text { (dois elos) }\end{array}$ & Não & Não \\
\hline Estratégia de outsourcing & $\begin{array}{c}\text { Bring in-house para } \\
\text { virtual }\end{array}$ & Virtual & Virtual \\
\hline Mercado & $\begin{array}{c}\text { - Local } \\
\text { - Corporativo e clientes } \\
\text { sofisticados }\end{array}$ & $\begin{array}{c}\text { - Local e incipiente } \\
\text { exportação } \\
\text { - Pequenas empresas e } \\
\text { clientes domésticos }\end{array}$ & $\begin{array}{l}\text { • Local } \\
\text { - Microempresas e } \\
\text { clientes domésticos }\end{array}$ \\
\hline Estratégia genérica & $\begin{array}{l}\text { Enfoque com } \\
\text { diferenciação }\end{array}$ & Custo & $\begin{array}{l}\text { Enfoque com } \\
\text { diferenciação }\end{array}$ \\
\hline
\end{tabular}


Utilizando o quadro teórico proposto por Chesbrough \& Teece (1996), todos os casos estudados se encontram no quadrante virtual, que, embora reflita uma tendência mundial para essa indústria, no caso brasileiro torna-se um imperativo pela ausência de competências locais nos elos a montante da cadeia (Figura 5). Esse aspecto reduz o grau de liberdade das opções estratégicas concernentes ao relacionamento com os demais elos da cadeia.

Destaca-se ainda que a dependência de fornecedores com maior poder de barganha, cujos itens representam grande parte dos custos de produção, reduzem sobremaneira as margens das empresas locais estudadas, que se mostraram significativamente dependentes de dispendiosas importações, a despeito do porte da empresa.

Essa dependência observada nos casos estudados aponta para o fato de que a indústria brasileira de PCs apresenta lacunas nos elos destacados como de maior valor agregado, fato que também tem impacto significativo na balança comercial, à semelhança do que ocorre na telefonia celular. A Figura 6 mostra a localização dos casos nos elos da cadeia da indústria de PCs.

Essa configuração também afeta a capacidade de inovação dessas empresas, restrita apenas a mudanças de sustentação (Christensen \& Overdorf, 2000), ou, conforme tipologia de Chesbrough \& Teece (1996), autônomas.

\section{Conclusões}

A indústria de PCs no Brasil passa por um momento importante de desenvolvimento, em contraste com o que acontece no mercado mundial, no qual houve redução no mercado de PCs nos últimos anos. Cresce a utilização do PC não somente pelas empresas de todos os tamanhos, mas também para o uso doméstico, este último fortemente impulsionado pela disseminação maior da Internet. Os casos "B" e "C", em especial, têm sido hábeis em explorar de maneira bastante significativa o crescimento do uso de computadores nas classes $\mathrm{C}$ e $\mathrm{D}$.

Ainda há oportunidades para empresas que se dedicam apenas à montagem de equipamentos, pois as barreiras à entrada são baixas. Nessas condições, as empresas podem ingressar nesse mercado sem maiores investimentos na produção de componentes eletrônicos, nem em pesquisa e desenvolvimento.

O caso "A" constitui a mais significativa exceção dessa situação, que é tanto produtora de PCs como de placas e de memórias DRAM, com investimentos significativos em pessoal e equipamentos.

O estudo exploratório indicou que a configuração mais comumente encontrada entre os fabricantes de PCs no Brasil é a de abordagem virtual. Contudo, para atingir o mercado potencialmente promissor, as empresas brasileiras necessitam adequar seus processos, levando em conta os aspectos de custos, qualidade e de atendimento, às especificidades dos mercados almejados: uso pessoal, pequenas empresas e grandes corporações. Essas decisões de natureza estratégica têm implicações importantes em termos de desenvolvimento de competências internas, envolvendo a adequada gestão da cadeia de suprimentos, de recursos humanos, de equipamentos e de força de vendas.

Tanto em âmbito brasileiro como mundial, deve-se observar que o processo de outsourcing, embora imprima responsividade e flexibilidade às empresas, também implica o aumento do nível de exposição aos riscos inerentes à perda de competências, principalmente no caso de inovações de ruptura e de natureza sistêmica. Para esclarecer qual a extensão dos riscos e dos perigos do outsourcing e detalhar as principais características ao longo da cadeia dessa indústria, são necessárias futuras pesquisas. 


\section{Referências Bibliográficas}

AMATO NETO, J.; CARVALHO, M. M.; LAURINDO, F. J. B.; GARCIA, R.; FLEURY, A. C. C. Análise das condições de desenvolvimento da indústria brasileira de semicondutores. São Paulo: Departamento de Engenharia de Produção da Escola Politécnica da Universidade de São Paulo, 2002. Disponível em: http://www.prd. usp.br/redecoop//artigo\%20final\%20bah\% 20poli\% 20jun\%202002r.pdf.

BOWERSOX, D. The strategic benefit of logistic. Harvard Business Review, July/Aug. 1990.

CARVALHO, M. M.; LAURINDO, F. J. B. Estratégias para competitividade. São Paulo: Futura, 2003. v. $1,254 \mathrm{p}$.

CARVALHO, M. M.; LAURINDO, F. J. B. Clustering and new product development: a Brazilian case. In: INTERNATIONAL ANNUAL CONFERENCE OPERATIONS MANAGEMENT AND THE NEW ECONOMY, 9., 2002, Copenhagen, Dinamarca. Proceedings... Copenhagen, Dinamarca, June 2002. p. 981-991.

CHANDRASHEKAR, A.; SCHARY, P. B. Toward the virtual supply chain: the convergence of IT and organization. International Journal of Logistics Management, v. 10, n. 2, p. 27-39, 1999.

CHESBROUGH, H. W.; TEECE, D. J. When is virtual virtuous? Harvard Business Review, v. 74, n. 1, p. 65-73, May/June 1996.

CHRISTENSEN, C. M.; RAYNOR, M.; VERLINDEN, M. Skate to where the money will be. Harvard Business Review, v. 79, n. 10, p. 72-81, Nov. 2001.

CHRISTENSEN, C. M.; OVERDORF, M. Meeting the challenge of disruptive change. Harvard Business Review, p. 66-76, Mar./Apr. 2000.

CLAVER, E.; GONZALEZ, R.; LLOPIS, J. An analysis of research in information systems (19811997). Information \& Management, v. 37, n. 4, p. 181-195, Apr. 2000.
DRUCKER, P. The discipline of innovation. Harvard Business Review, v. 79, n. 6, p. 149-159, Nov./Dec. 1998.

LAURINDO, F. J. B.; CARVALHO, M. M. Disruptive changes of PC industry in the Brazilian context. In: JOINT INTERNATIONAL CONFERENCE: ONE WORLD? ONE VIEW OF OM?, 1., 2003, Villa Erba, Lake Como, Italy. The challenges of integrating research and practices. Proceedings... Villa Erba, Lake Como, Italy, June 2003.

LUNDVALL, B. A. Introduction. In: LUNDVALL, B.-A. (Ed.). National systems of innovation: towards a theory of innovation and interactive learning. London: Pinter, 1992.

MELO, P. R. S.; RIOS, E. C. S. D.; GUTIERREZ, R. M. V. Componentes eletrônicos: perspectivas para o Brasil. BDES Setorial, Rio de Janeiro, n. 13, p. 3-64, mar. 2001.

PORTER, M. E. How competitive forces shape strategy. Harvard Business Review, p. 137-145, Nov./Dec., 1979.

PORTER, M. E.; MILLAR, V. E. How information gives you competitive advantage. Harvard Business Review, v. 63, n. 4, p. 149-160, July/Aug. 1985.

PRAHALAD, C. K.; HAMEL, G. The core competence of the corporation. Harvard Business Review, p. 79-91, May-June 1990.

REID, D. R.; SANDERS, N. R. Operations management. New York: John Wiley \& Sons, 2002.

SACHS, J. Your IBM PC: made easy. New Delhi: McGraw-Hill, 1986.

SIKONOWICZ, W. Guide to IBM PC personal computer. New Delhi: McGraw-Hill, 1986.

YIN, R. K. Case study research: design and methods. Newbury Park: Rev. Ed. Sage Publications, 1991.376 


\title{
THE DISRUPTION OF THE BRAZILIAN PERSONAL COMPUTER (PC) INDUSTRY: A MULTIPLE CASE STUDY
}

\begin{abstract}
Although the personal computer $(P C)$ appeared in the seventies, this industry really boomed only after IBM launched its PC, in 1981. Through an aggressive outsourcing strategy, IBM rapidly conquered the market, but this strategy also caused lost of internal competences to its main partners, Intel and Microsoft and also to autonomous vendors. Many PC manufacturers have appeared since then. In Brazil, nowadays, PC industry is relegated to assemble imported kits, with small value locally added and also to manufacture final steps of components production. After the end of a protectionist law characterized by the abrupt exposure to foreign competitors, the Brazilian PC and semiconductors industries collapsed. To achieve insertion in the global chain, Brazilian companies need to cope with the qualification performance criteria to participate in the outsourcing process.Based on a theoretical background that encompasses outsourcing, innovation, value and the evolution of PC industry, this paper intends to investigate the Brazilian PC industry competitiveness and the constraints to its insertion in the global market. The adopted methodological approach was multiple cases, whose selection criteria were: different roles in the value chain; the degree of verticalization; the main market aimed and company size.
\end{abstract}

Key words: outsourcing, innovation, personal computer industry, competitive strategy. 